\title{
Evaluation of Preservation Effect by Aquo-Siloxane Method towards Water Permeation and Material Diffusion into Porous Rocks
}

\author{
Akira Sato1, Minami Egashira'2, Michiyo Obata² \\ ${ }^{1}$ Graduate School of Advanced Science and Technology, Kumamoto University, Kumamoto, Japan \\ ${ }^{2}$ Kyushu Research Institute for Cultural Properties Inc., Kumamoto, Japan \\ Email: asato@kumamoto-u.ac.jp
}

How to cite this paper: Sato, A., Egashira, M. and Obata, M. (2017) Evaluation of Preservation Effect by Aquo-Siloxane Method towards Water Permeation and Material Diffusion into Porous Rocks. Materials Sciences and Applications, 8, 419-435. https://doi.org/10.4236/msa.2017.86029

Received: March 31, 2017

Accepted: June 4, 2017

Published: June 7, 2017

Copyright ( 92017 by authors and Scientific Research Publishing Inc. This work is licensed under the Creative Commons Attribution International License (CC BY 4.0).

http://creativecommons.org/licenses/by/4.0/

\section{(c) (7) Open Access}

\begin{abstract}
Various kinds of heritages, such as architectures, statues, grave posts and towers, are made by stone, and they are facing the crisis of weathering. Therefore, it is necessary to give appropriate treatments to keep them in good conditions. Kyushu Research Institute for Cultural Properties Inc. and $\mathrm{Ku}-$ mamoto University introduced a new method, Aquo-Siloxane Method, in order to protect the stone heritages. In this study, preservation effect by AquoSiloxane method towards water permeation and material diffusion was verified. Here one-dimensional permeation and diffusion tests were conducted, and the intrinsic permeability and diffusion coefficient of rock samples with and without Aquo-Siloxane treatments were evaluated. As rock samples, 3 types of sandstones and concrete were applied. It was found that the permeability decreased to less than $1 / 10$ to $1 / 100$ of without Aquo-Siloxane treatment, and that the effect gradually developed during more than one year. One-dimensional diffusion tests were also conducted, and the diffusion process in rock samples are visualized by X-ray CT scanner system. It was confirmed internal structures of samples are clearly visualized, and that the diffusion process was also visualized as X-ray CT images. In order to extract the necessary information due to diffusion, image subtraction method was applied to image data. Then, by comparing obtained CT image data and numerical solutions, diffusion coefficients of rock samples with and without Aquo-Siloxane treatments were evaluated. As a result, diffusion coefficients also became smaller by applying Aquo-Siloxane treatments. It is revealed that material movement due to diffusion was also efficiently suppressed by applying Aquo-Siloxane method. Finally, Aquo-Siloxane method was applied to a stone heritage. It was found that no more chippings and cracks were observed and that the heritage has been kept in good condition for at least four years.
\end{abstract}




\section{Keywords}

Aquo-Siloxane Method, Stone Heritages, Water Permeation, Diffusion, X-Ray CT

\section{Introduction}

In both western and eastern culture, stones and rocks are important construction materials. Not only the buildings but also various kinds of heritages, such as stone architectures, stone statues, grave posts and stone towers, have been made and preserved all over the world. In many cases these heritages are located outside and influenced by the weathering. Therefore, the assessment of the heritages is the first step to keep heritages in good conditions [1] [2] [3] [4]. Generally weathering is caused by many different reasons. For example, freezing and thawing give strong impacts to the rock structures in the cold district [5] [6]. Biodeterioration is also another serious factor in the warm district [7]. However, in most of the cases, existence of water in rock structure is thought to be the main reason of weathering. Here, it is also known that not only the water but the solute which is involved in the water gives serious damages. The appropriate assessment of weathering due to the water and solute flow is important to preserve stone heritages, and several researches have been conducted [8] [9] [10]. It is also necessary to give proper treatment towards stone structures in order to keep heritages in good conditions. Walker et al. [11] applied protection afforded by self-assembled fatty acid and fluorinated mixed allayers on calcite, and it was effective to suppress sulfuric acid permeation. Bugani et al. [12] conducted the treatment towards biocalcarenite using polymers, and structural change inside of the rock sample is evaluated by $\mu$-focus X-ray CT data. In Japan, reinforcement material based on orthosilicic acid ethyl ester has been used. However, there are still problems such as exfoliation at the border between the reinforcement and rock matrix or durability.

Kyushu Research Institute for Cultural Properties Inc. and Kumamoto University have been introduced a new method, Aquo-Siloxane Method, in order to protect the stone heritages [13]. The procedure of the method is very simple. Here the treatment material, Aquo-Siloxane, is painted on the surfaces of materials several times. The Aquo-Siloxane will penetrate into the stone pores. Then, the water which exists in stone structures is captured by the material and it becomes stable. By applying this method, it is expected that Aquo-Siloxane will prevent the water permeation and material movement due to the diffusion, or will reduce the speed of the permeation and diffusion. This method has been applied to several stone heritages, however, mechanical properties have not been clearly revealed yet, and its quantitative and mechanical evaluation of the effect is few.

In this study, improvement effect on the permeability and material diffusion characteristics in porous rocks by applying Aquo-Siloxane method is evaluated. 
As for the permeability, one-dimensional permeation tests are conducted towards the rock samples with the Aquo-Siloxane treatment and without the treatment, and the intrinsic permeability of samples are evaluated. Moreover, one-dimensional diffusion tests are also conducted towards the samples with and without the treatment using solution of potassium iodide (KI) as a tracer, and the diffusion process in rock samples is visualized by applying X-ray CT scanner systems. Here, the macroscopic diffusion phenomena in several $\mathrm{mm}$ order is visualized by industrial X-ray CT system, and diffusion coefficients of samples are evaluated from the CT mage data. By comparing obtained data, the effect is evaluated and applicability of Aquo-Siloxane is also discussed.

\section{Aquo-Siloxane Method}

Kyushu Research Institute for Cultural Properties Inc. has been developing Aquo-Siloxane Method as a new method to preserve various kinds of heritages. The characteristic point of the method is to utilize the existence of water in the materials [13]. In the previous preservative treatment, demineralization treatments are inevitably necessary since the solute in the materials cause corrosion. In the Aquo-Siloxane method, however, demineralization treatment process is not necessary, and it can be applied to not only stone structures but also woods and metals in the same procedure. Aquo-Siloxane method utilizes a hydroxyl group or ions, and it can control the moisture condition in the materials.

Aquo-Siloxane is transparent and colorless liquid as shown in Figure 1. Aquo-Siloxane treatment consists of two kinds of amphipathic compounds, that is, polyether siloxane and alkoxysilane. Both compounds contain hydrophobic and hydrophilic components. Polyether siloxane migrates in porous media by searching moisture, and moisture is taken in polyether siloxane. Alkoxysilane is carried by polyether siloxane in porous media, and it gets into small pores. Then, it becomes stabilized by bonding with hydroxyl groups.

The procedure of the treatment is much easier than previous methods. Kyushu Research Institute for Cultural Properties Inc. recommends following procedure. At first, Aquo-Siloxane is painted on the surfaces 5 times. If the material is permeable materials such as porous rocks, enough Aquo-Siloxane is painted in order for Aquo-Siloxane to permeate into objects. After the objects are left for one day, some water is sprinkled on the painted surface, then this process is repeated 5times every 30 minutes. After the treatment, the temperature and moisture control is not necessary, and it is a big advantage than previous methods.

\section{One-Dimensional Permeation Test}

\subsection{Darcy's Law}

Permeation tests of rock samples are conducted under the full water saturated condition. In this case, water permeation obeys following Darcy's law.

$$
u=-\frac{k}{\mu} \frac{\mathrm{d} p}{\mathrm{~d} x}
$$




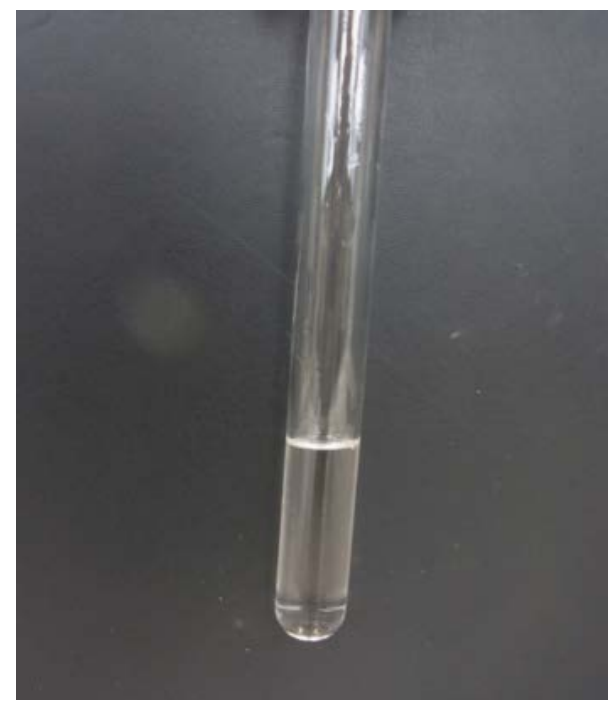

Figure 1. Protection solution of Aquo-Siloxane.

Here, $u$ is flow velocity which is defined as the water volume which go through unit area during unit time. $\mu$ is viscosity of fluid and $\mathrm{d} p / \mathrm{d} x$ is pressure gradient in the $\mathrm{X}$-axis (nominal flow) direction. The value $k\left[\mathrm{~m}^{2}\right]$ is intrinsic permeability, and it represents how easy/difficult the water permeates in porous media. In other words, this represents the geometry of water permeation path. When the fluid is water, $\mu$ is determined as a function of temperature. In this study, the values of $k$ of rock samples under the conditions with and without Aquo-Siloxane treatment conditions are evaluated by measuring flow velocity $u$ and pressure gradient $\mathrm{d} p / \mathrm{d} x$.

\subsection{Permeation Tests}

\subsubsection{Experimental Apparatus}

Authors have conducted one-dimensional permeation tests towards rock samples under the different conditions [14] [15] [16]. In this study, same apparatus and procedures are applied in order to evaluate intrinsic permeability of rock samples. Experimental apparatus for one dimensional permeation tests is shown in Figure 2. This system consists of two syringe pumps and a pressure vessel. Two syringe pumps are TELEDYNE ISCO Inc. 500D Syringe pumps, and they are installed both end of a pressure vessel. Maximum available pressure condition is $25 \mathrm{MPa}$, and the capacity of the syringe is $500 \mathrm{ml}$. The pumps can also control the flow rate in the range of $0.001-204 \mathrm{ml} / \mathrm{min}$. The pressure vessel is made of carbon fiber reinforced plastic (CFRP) tube and the flanges made of aluminum are fixed by four shafts at both ends. As Figure 2 shows, rock sample is installed inside of the vessel. In this case, rock sample is surrounded by working fluid. Therefore, the inlet pressure of the fluid and the confining pressure are simultaneously acting on the specimen in this permeation system.

As Equation (1) shows, it is necessary to measure flow velocity $u$ and pressure gradient $\mathrm{d} p / \mathrm{d} x$ in order to evaluate intrinsic permeability $k$. When the value of $k$ is expected smaller than $10^{-16} \mathrm{~m}^{2}, \mathrm{~d} p / \mathrm{d} x$ is fixed and $u$ is measured. On the other 


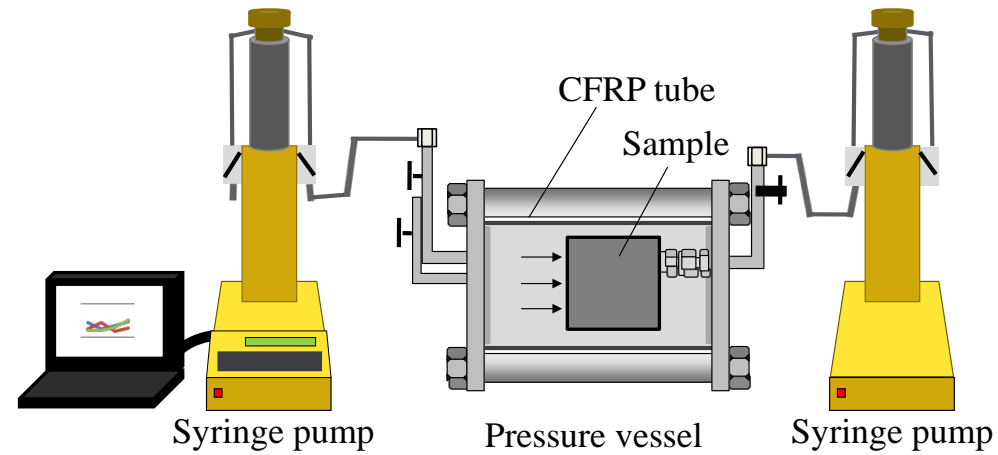

Figure 2. Experimental apparatus for one dimensional permeation tests. This system consists of pressure vessels made by CFRP (Carbon Fiber Reinforced Plastic) and two syringe pumps.

hand, when the value of $k$ is expected larger than $10^{-16} \mathrm{~m}^{2}, u$ is fixed and $\mathrm{d} p / \mathrm{d} x$ is measured. As for the details of the apparatus and the procedure, please refer Sato and Ikeda [14].

\subsubsection{Rock Samples for Permeation Tests}

Schematic model of rock samples for one-dimensional permeation tests is shown in Figure 3. The geometry is same as the samples by Sato and Ikeda [14]. The length and diameter are approximately $50 \mathrm{~mm}$ and $50 \mathrm{~mm}$ respectively. The side of the sample is completely sealed by epoxy resin. The porous stone and drain pipe are installed on one end of the sample. The surface is also sealed by epoxy resin. Another end is free and the fluid is injected from this free surface into rock sample. Therefore the one dimensional fluid flow can be simulated. This type of sample is installed in the pressure vessel as Figure 2.

As representatives of porous rocks samples, following 4 types of rocks were chosen; Berea sandstone, Kimachi sandstone, Isahaya sandstone and Concrete. Berea sandstone is produced at Ohaio, U.S.A., and Isahaya and Kimachi sandstone are produced in Japan. Approximate porosities of samples are 24\%, 19\%, $12 \%$ and $12 \%$ respectively. These porosities were evaluated by the weight differences between completely dry and water saturated conditions.

\subsection{Effect of Aquo-Siloxane Method towards Permeability of Rocks}

Intrinsic permeability of same rock types without Aquo-Siloxane treatment has already been evaluated by Sato and Ikeda [14]. Here, the effects of Aquo-Siloxane method towards the permeability of rocks are discussed. The temporal changes of permeability or rock samples with Auo-Siloxane treatment are measured during 200 days to 600 days, and the results are shown in Figure 4. Here, the value of $k$ at 0 day represents the results without Aquo-Siloxane treatment. As these figure shows, the value of intrinsic permeability is decreasing gradually in all rock samples during 200 to 600 days. It means that the Aquo-Siloxane develops the effect towards permeability gradually, and it continues more than one year. After several hundred days, the value of $k$ become reaches less than 1/10 to 


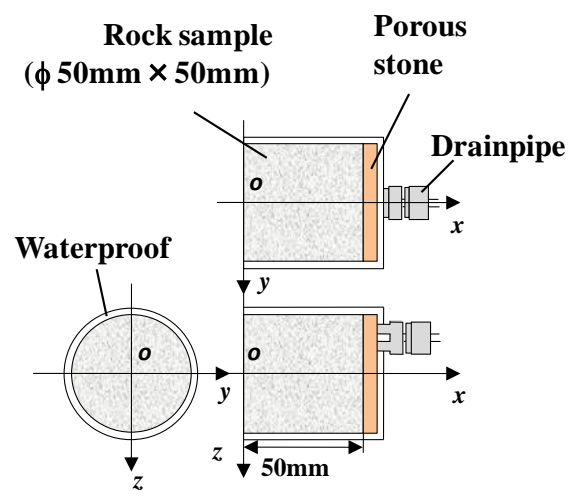

Figure 3. Rock sample for one-dimensional permeation tests.

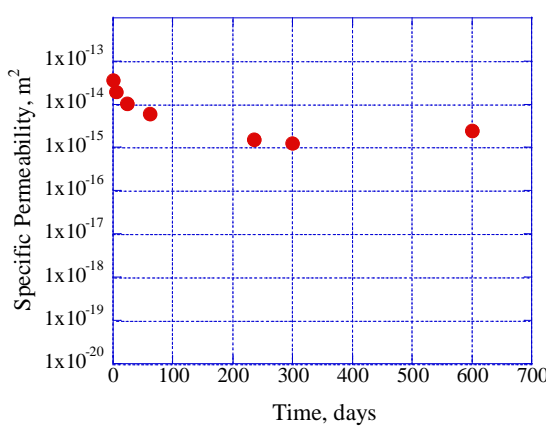

(a)

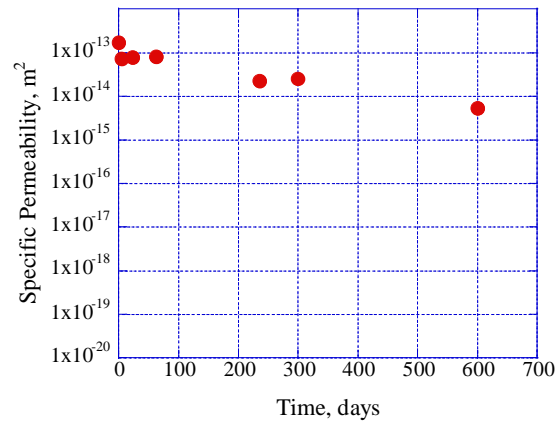

(c)

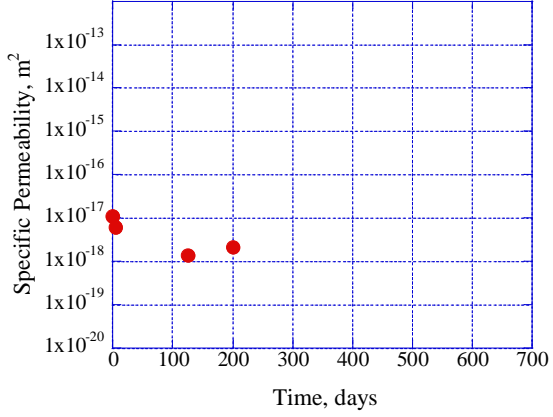

(b)

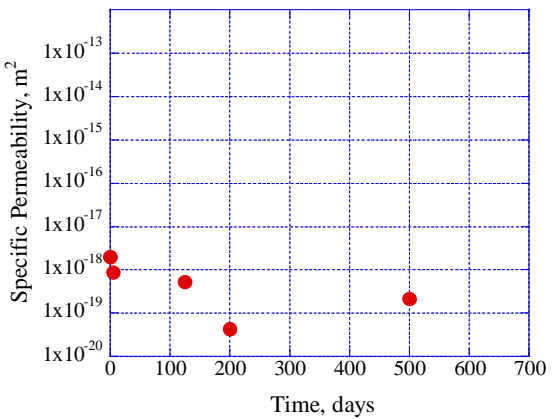

(d)

Figure 4. Temporal change of permeability of rocks after Aquo-Siloxane treatment. (a) Berea sandstone; (b) Kimachi sandstone; (c) Isahaya sandstone; (d) Concrete.

1/100 of without Aquo-Siloxane treatment. It represents that Aquo-Siloxane method does not shut out the movement of water but it reduces or mitigates the water permeation. Therefore, it is expected that the Aquo-Siloxane treatment prevent from sudden moisture changes in the stone heritages and that it keeps heritages in relatively stable moisture conditions.

\section{X-Ray CT Scanner Systems}

$\mathrm{X}$-ray CT is the technique to visualize the density distribution inside of the object, and it has been applied not only to the medical field, but also to various engineering fields. Geoengineering including rock mechanics is also the field where X-ray CT is efficiently applied [17] [18]. In this study, X-ray CT scanner is ap- 
plied for observation of rock samples, especially for visualization and analysis of diffusion phenomena. Then the effect of the Aquo-Siloxane method is verified.

Research group, X-Earth Center of Kumamoto University in which authors belongs to, is operating two types of X-ray CT systems, such as industrial X-ray CT scanner and $\mu$-focus X-ray CT scanner. Industrial X-ray CT scanner has relatively higher X-ray tube energy, and it is suitable to visualize relatively large samples or relatively high density materials. On the other hands, $\mu$-focus X-ray CT scanner is the suitable to observe very small region. As its name suggests, several $\mu \mathrm{m}$ order of observation is possible. As for the details including specs and tomography conditions, please refer paper [19] and [20]. In this study, macroscopic or nominal diffusion phenomena in $\mathrm{cm}$ order are visualized by industrial X-ray CT scanner.

\section{One-Dimensional Diffusion Tests}

In this study, one-dimensional diffusion tests are also conducted towards rock samples with and without Aquo-Siloxane treatment. Then the phenomenon which happens in rocks or in the pores of rock sample is visualized by X-ray CT scanners, and its effect is verified.

\subsection{Theory}

Diffusion is the phenomena that solute moves according to the concentration gradient. Generally it is expressed by Fick's law.

$$
\frac{\partial c}{\partial t}=D \frac{\partial^{2} c}{\partial x^{2}}
$$

here, $c$ is concentration of solution, $D$ is diffusion coefficient, $t$ is time and $x$ is the nominal direction of diffusion. In this study, one-dimensional diffusion tests are conducted and this process is visualized by X-ray CT method. Then, diffusion coefficient $D$ of rock samples with and without Aquo-Siloxane treatment is evaluated.

Diffusion is the movement of solute, and nominal movement is expressed as concentration of solution as Equation (2) shows. In the X-ray CT method, density distribution of solute can be visualized. However, the concentration of solute is proportional to the density, and the change of concentration can be also visualized by X-ray CT method.

\subsection{Rock Samples for One-Dimensional Diffusion Tests}

Geometry of rock samples for diffusion observations is shown in Figure 5. Fundamental geometry of the samples is almost same as the ones for permeation tests, however, it has only one free surface and the other faces are completely sealed by epoxy resin. Therefore, solute can diffuses into rock sample only from the free surface. As rock samples, same types of rock samples used by one-dimensional permeation tests, such as Berea sandstone, Isahaya sandstone, Kimachi sandstone and Concrete, are also used in the diffusion test. In all cases, the size of the rock sample is $50 \mathrm{~mm}$ in diameter and $50 \mathrm{~mm}$ in length. X-ray CT im- 


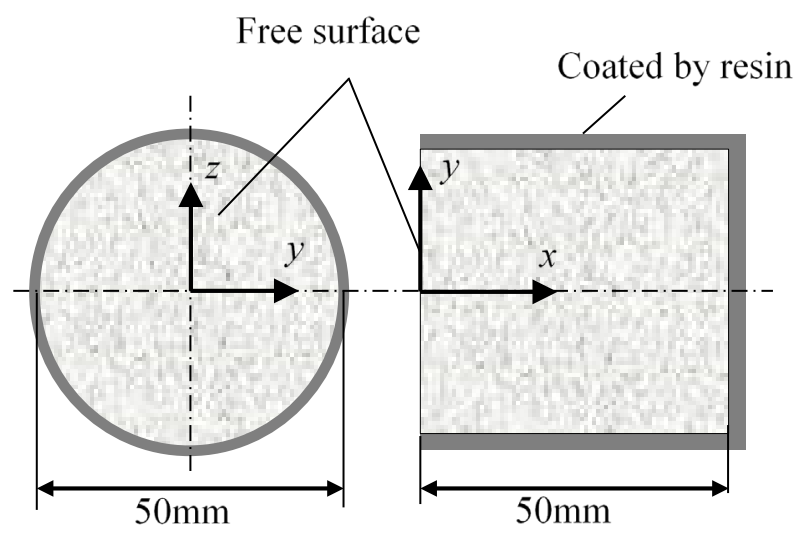

Figure 5. Rock sample for macroscopic diffusion tests.

ages of rock samples before diffusion tests are shown in Figure 6. These images are taken along cylindrical axis. Generally in X-ray CT images, brighter region represents the higher density region and darker region represents lower density region. As these figures show, the internal structures of rock samples are clearly visualized. In the case of Berea sandstone, sedimentary layers are clearly confirmed. It is confirmed that the Kimachi sandstone consists relatively larger grains compare with Isahaya sandstone. Usually harder rocks are used as aggregates in Concrete. Therefore, aggregates are expected to have higher density than mortal part. The existences are also clearly visualized.

\subsection{Procedures of One-Dimensional Diffusion Tests}

Sato and Ikeda [14] conducted one-dimensional diffusion tests and introduced a series of procedure to evaluate diffusion coefficient from X-ray CT image data. The same procedures are also taken in this study.

Schematic of macroscopic diffusion observation is shown in Figure 7. Initially, rock samples are fully saturated by water in both condition of with and without Aquo-Siloxane treatment. These rock samples are put in the tracer, then the tracer diffuses into samples from free surface. For the comparison, diffusion tests are conducted using same rock type sample with and without Aquo-Siloxane treatment simultaneously as Figure 7 shows.

As stated before, X-ray CT method is the one to visualize density distribution. Therefore, in order to visualize diffusion phenomena by X-ray CT scanner, it is necessary to give enough density change during diffusion process which X-ray CT scanner system can detect. In this study, KI (potassium iodide) solution is applied as a tracer. Here, $30 \%$ of $\mathrm{KI}$ solution is used for diffusion tests. The value corresponds to the density of $1254 \mathrm{~kg} / \mathrm{m}^{3}$. KI solution also has the characteristics that it is hardly adsorbed to rocks. Therefore, it is well known as one of the representative tracers, and it is suitable for the detection of water flow and diffusion phenomena [21] [22] [23].

\subsection{X-ray CT Images during Diffusion Tests}

The examples of CT images during diffusion test are shown in Figures 8-11. In 


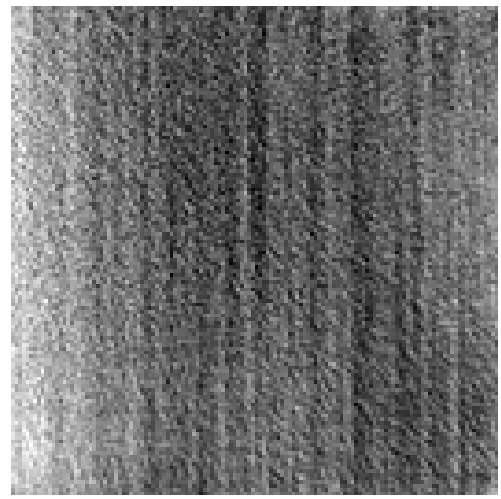

(a)

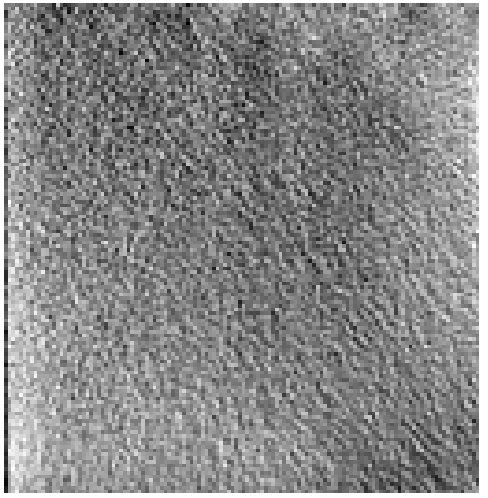

(c)

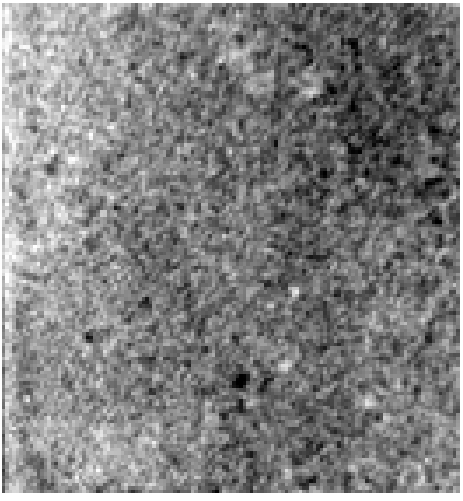

(b)

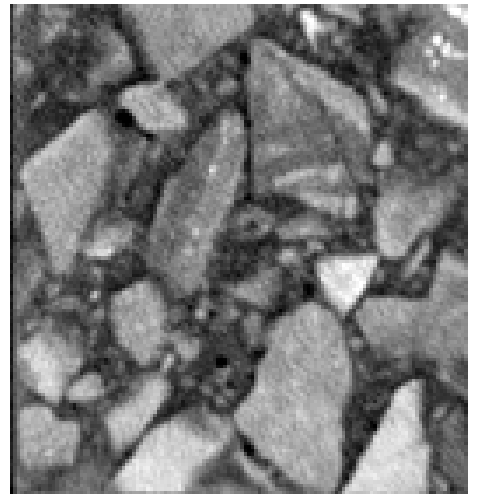

(d)

Figure 6. X-ray CT images of rock samples. (a) Berea sandstone; (b) Kimachi sandstone; (c) Isahaya sandstone; (d) Concrete.

Sample with

Aquo-Siloxane treatment

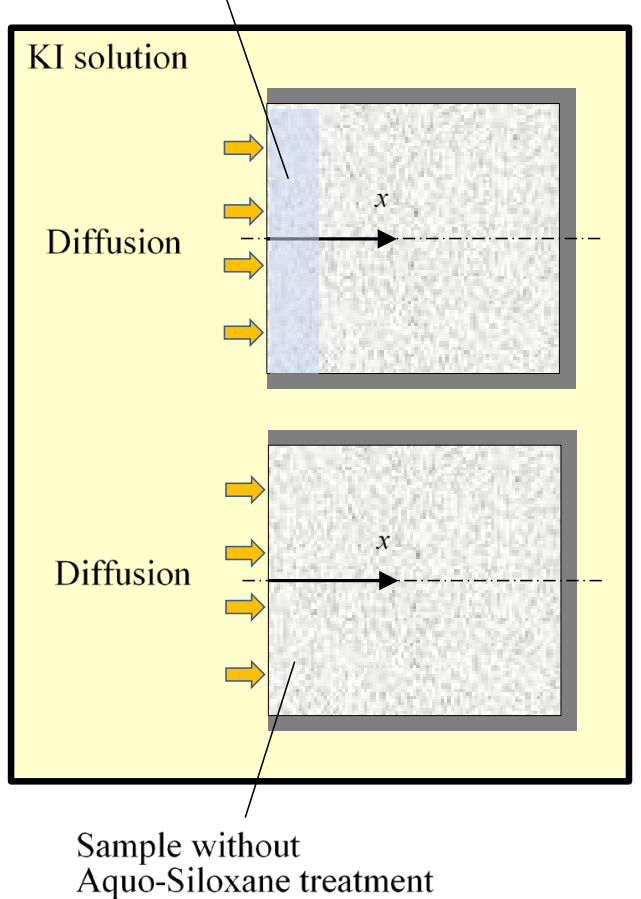

Figure 7. Schematic of macroscopic 1D diffusion tests. 


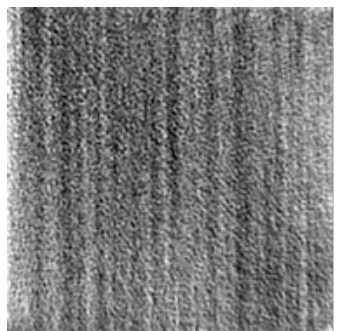

(a)

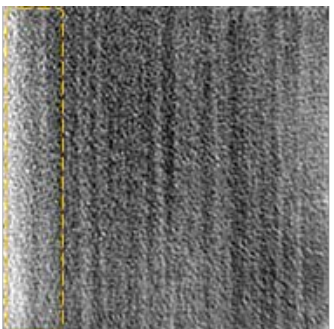

(b)

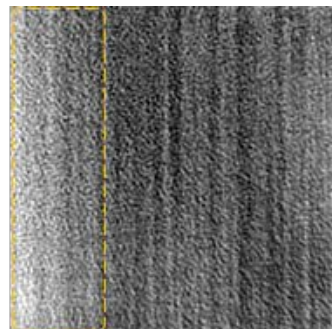

(c)

Figure 8. X-ray CT images during diffusion tests, Berea sandstone. (a) 10 minute; (b) 3 hours; (c) 7 hours.

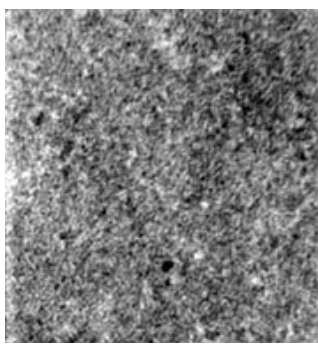

(a)

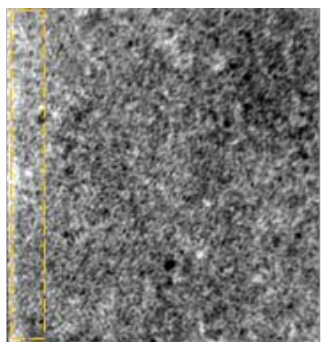

(b)

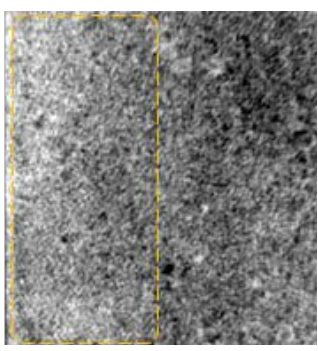

(c)

Figure 9. X-ray CT images during diffusion tests, Kimachi sandstone. (a) 10 minute; (b) 3 hours; (c) 30 hours.

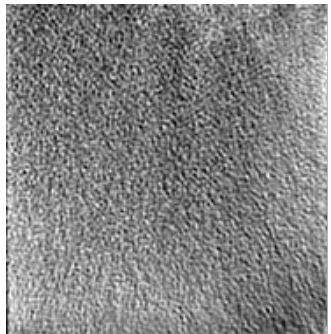

(a)

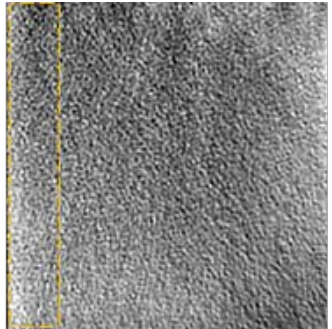

(b)

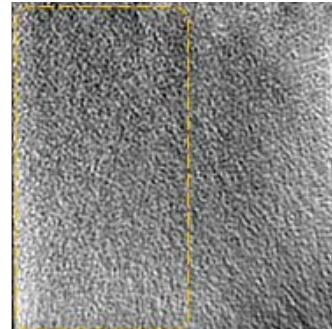

(c)

Figure 10. X-ray CT images during diffusion tests, Isahaya sandstone. (a) 10 minute; (b) 3 hours; (c) 7 hours.

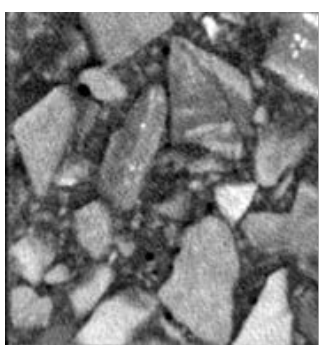

(a)

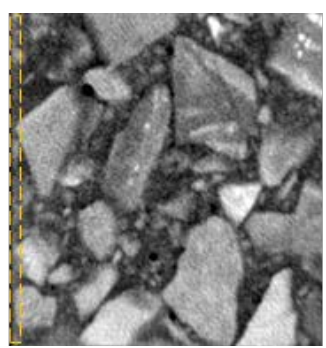

(b)

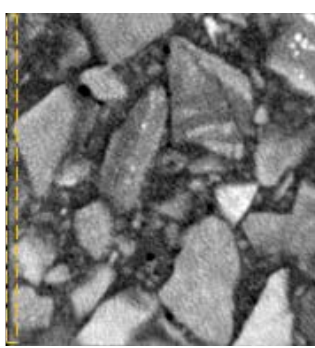

(c)

Figure 11. X-ray CT images during diffusion tests, Concrete. (a) 10 minute; (b) 3 hours; (c) 30 hours.

the case of Berea sandstone and Isahaya sandstone, diffusion occurs relatively fast and the diffusion tests were conducted for 7 hours. On the other hands, in the case of Kimach sandstone and Concrete, diffusion is very slow and tests were 
conducted for 30 hours. In each image, left hand side is the free surface and the solute diffuses intro rock sample from this surface. In the figures, inside of the dotted line is the region where density is increased due to diffusion. In the case of Berea sandstone and Kimachi sandstone, it is relatively easy to confirm the diffused region. However, generally rock samples have strong heterogeneity and the density change itself due to the diffusion is small, and it is difficult to identify the diffused region in many cases.

In this study, image subtraction method is applied in order to extract the necessary information due to diffusion [14]. As is stated before, X-ray CT images were taken before and after commencement of diffusion tests. This is the technique to conduct subtraction between an image at initial condition and images after commencement of diffusion tests, and it is known as efficient technique to extract necessary information, that is change of density.

\subsection{Evaluation of Diffusion Coefficient}

Sato and Ikeda [14] introduced the method to evaluate diffusion coefficient $D$ from the CT image data taken during diffusion tents. Firstly, one dimensional concentration distribution in the $\mathrm{X}$-axis is detected from X-ray CT images. On the other hand, theoretical concentration distribution can be calculated from Equation (2). Here, diffusion coefficient $D$ is evaluated by comparing experimental results and numerical solutions of concentration profiles as Sato and Ikeda [14] shows.

As representative examples, X-ray CT images after image subtraction and the concentration profiles of Berea sandstones are shown in Figure 12 and Figure 13. The mean concentration value along the nominal diffusion direction (X-axis direction in Figure 5) is evaluated from the subtracted CT images. These are concentration profiles 7 hours after commencement of diffusion tests. In these figures, concentration in rock sample $\mathrm{C}$ is normalized by the concentration of solute $C_{0}$. As these figures show, amount of solute which diffuses into rock sample is smaller in the case of rock sample with Aquo-Siloxane treatment. In the case of the sample without Aquo-Siloxane treatment, solute diffuses into approximately $20 \mathrm{~mm}$ from inlet free surface. However, in the case of sample with the treatment, diffusion area is limited up to approximate $10 \mathrm{~mm}$. The mean value of concentration increment of the sample with the treatment is also smaller than the one without treatment. The same tendency is also confirmed in the other rock samples, and it is confirmed that the diffusion of solute is obviously suppressed by Aquo-Siloxane treatment.

As stated before, diffusion coefficients of 4 types of rock samples with and without Aquo-Siloxane treatment are evaluated. Here, we would like to discuss the relation between intrinsic permeability and diffusion coefficient before and after applying Aquo-Siloxane treatment. The results are shown in Figure 14. This figure shows the relation between diffusion coefficients and intrinsic permeability. The values of intrinsic permeability are obtained at one-dimensional permeation tests stated before. It is found that values of both intrinsic permea- 


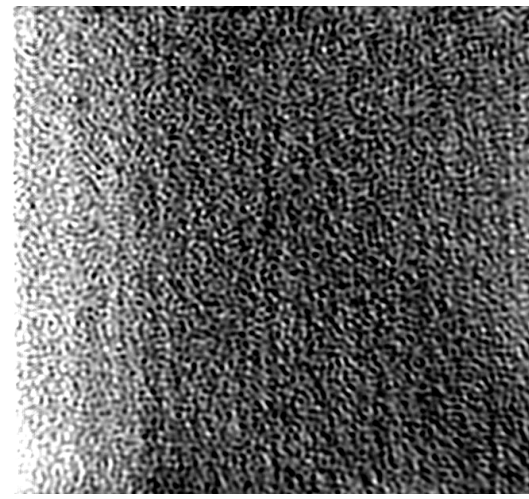

(a)

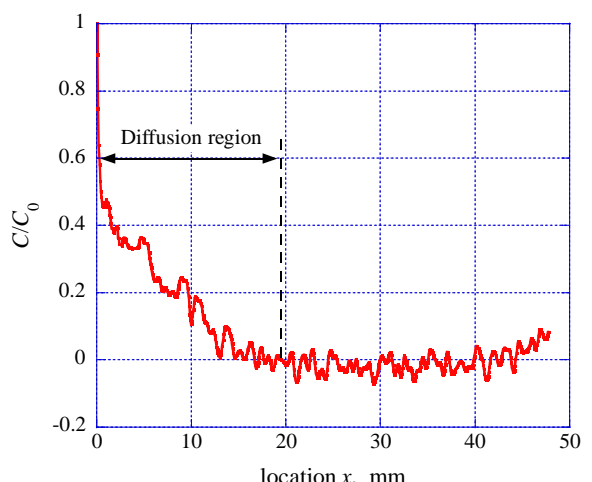

(b)

Figure 12. Concentration profile evaluated from X-ray CT image data without AquoAiloxane treatment. (a) X-ray CT image after image subtraction. The brighter region represents the region where density is increased due to diffusion; (b) Distribution of normalized mean increment of concentration.

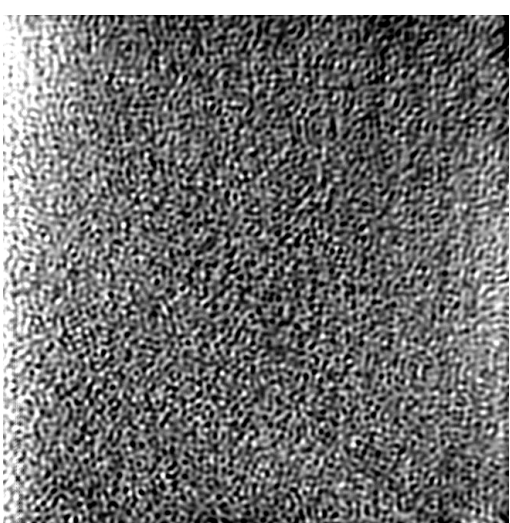

(a)

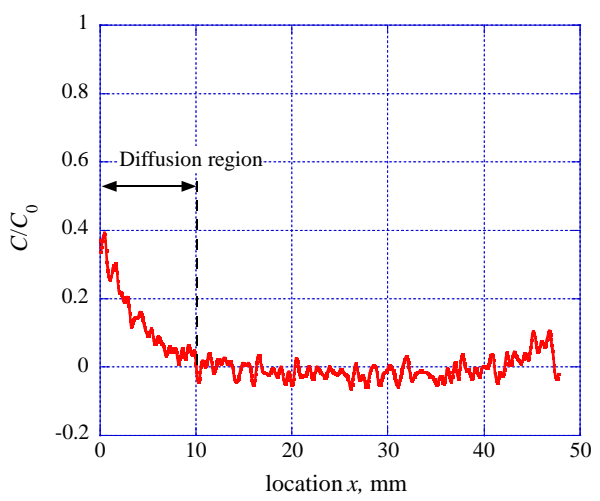

(b)

Figure 13. Concentration profile evaluated from X-ray CT image data with AquoAiloxane treatment. (a) X-ray CT image after image subtraction. The brighter region represents the region where density is increased due to diffusion; (b) Distribution of normalized mean increment of concentration.

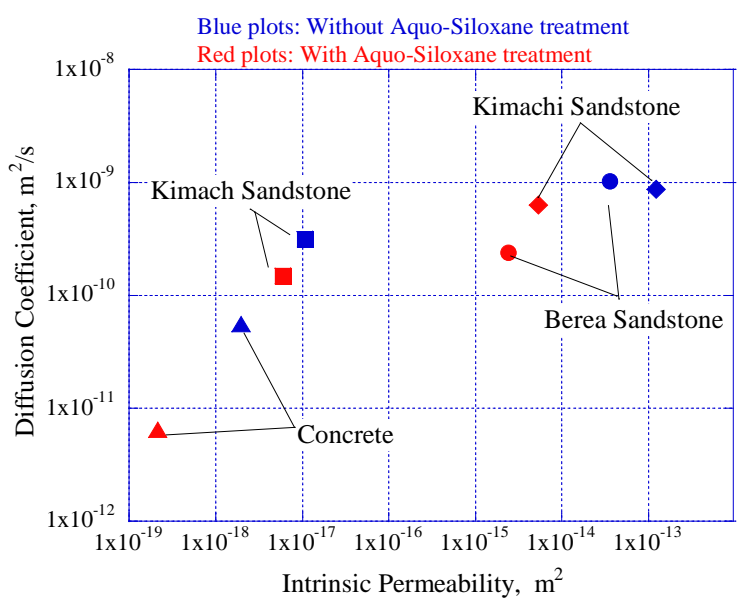

Figure 14. Relation between intrinsic permeability and diffusion coefficient of rock samples with and without Aquo-Siloxane treatment. 
bility and diffusion coefficients are decreased by applying Aquo-Siloxane treatment. In the case of intrinsic permeability, even though the difference of the value of Kimachi sandostone is smaller than the other samples, the value decreases to approximately $1 / 10$ to $1 / 100$ of the one without the treatment. In the case of diffusion coefficient, the change is not so larger, however, all values are decreased by applying the treatment. Therefore, it is revealed that water permeation and material movement due to diffusion is efficiently suppressed by applying Aquo-Siloxane method.

Micro scale observations of solute in porous rock samples have been conducted by Sato et al. [24]. Here, diffusion phenomena in rock samples with and without Aquo-Siloxane treatment were visualized by $\mu$-focus X-ray CT system. It was shown that solute migrates relatively large pores and that the solute hardly diffuses into pores by applying Aquo-Siloxane treatment. They also estimated that amount of diffused solute after applying Aquo-Siloxane treatment became almost $1 / 2$ to $1 / 3$ of without Aquo-Siloxane treatment. The results coincide with the change of diffusion coefficients before and after applying Aquo-Siloxane treatment.

In this way, Aquo-Siloxane method does not shut out the movement of solute but it reduces or mitigates the diffusion same as the effect to water permeation. In other words, Aquo-Siloxane can keep stone heritages in relatively stable condition.

\section{Application Example to the Preservation of Tone heritage}

Even though the Aquo-Siloxane is a new method, there are several application examples in order to preserve or protect stone heritages. Here, a case which the Aquo-Siloxane treatment was applied is introduced. The sample is 10 stories stone tower as shown in Figure 15. It is a part of ruined temple which located at Manno town in Kagawa Prefecture, Japan. The heritage is now also registered as

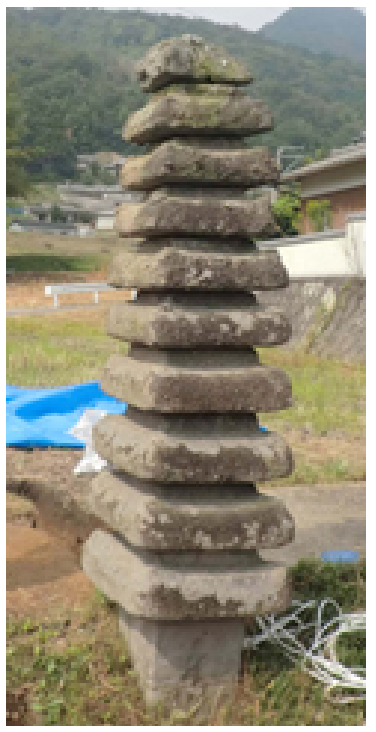

Figure 15. Stone tower made by tuff breccia before applying Aquo-Siloxane method. 
one of a national heritages of Japan. The height is approximately $2.5 \mathrm{~m}$, and most of parts are made by tuff breccia. It is estimated that this tower was built approximately 700 years ago. As Figure 15 shows, the tower has been located outside since it was built. Therefore, it is strongly damaged by weathering and some parts have been already chipped and fallen down. Towards the stone tower, several preservation treatments including Aquo-Siloxane methods were applied in 2012. The lost and chipped parts are restored and fixed by same kind tuff breccia as shown in Figure 16. Then, the Aquo-Siloxane was painted on the all surfaces of the stone tower. The condition of the tower one year and four years after the treatments are shown in Figure 17. As these figure show, the stone tower is kept in good condition during four years, and no more chipping and cracks have been observed. It depends on the weather condition the stone tower after AquoSiloxane treatment looks keeping moisture or watery. It is a characteristic point

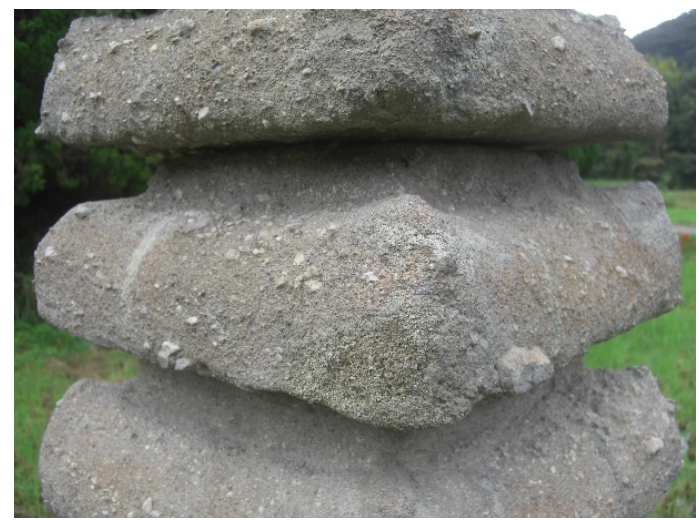

Figure 16. Restored and fixed part of the stone tower.

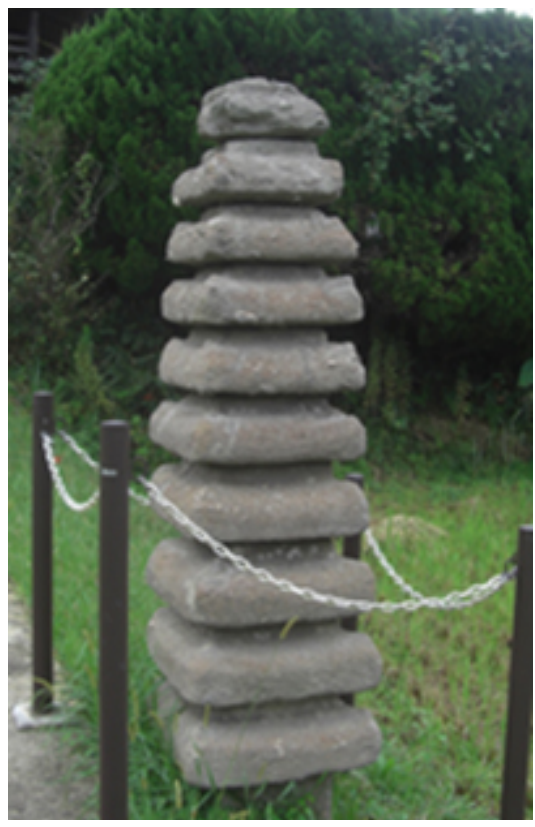

(a)

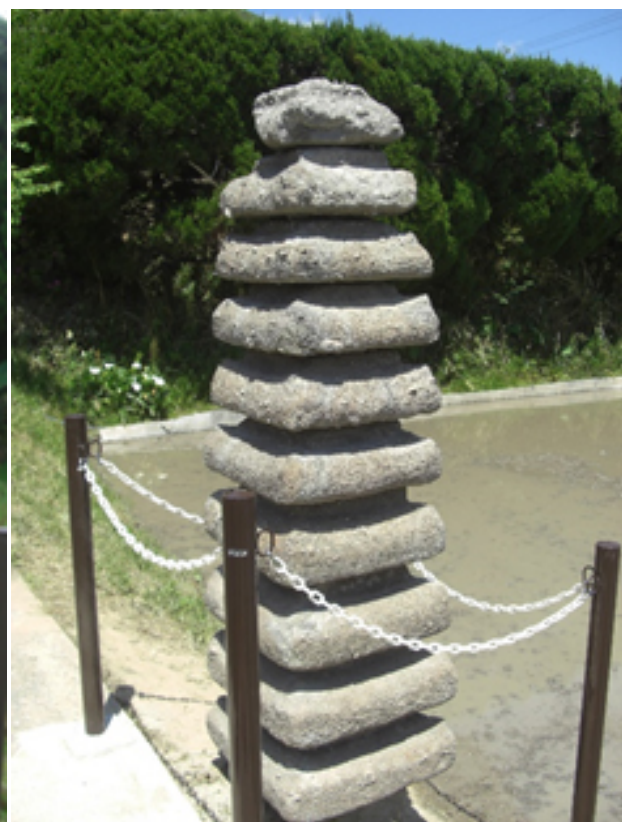

(b)

Figure 17. Stone tower after preservation treatments including Aquo-Siloxane treatment. (a) After one year; (b) After four years. 
of Aquo-Siloxane treatment when it is applied to stone materials. This is because that Aquo-Siloxane treatment reduces or mitigates the water permeation stated before in this study. In order to hand historical heritages down to posterity, it is necessary to keep them in good condition for long time. Authors will also continue to observe the heritages and to verify the effect of Aquo-Siloxane treatment in future.

\section{Conclusions}

Kyushu Research Institute for Cultural Properties Inc. and Kumamoto University have been introduced a new method, Aquo-Siloxane Method, in order to protect the stone heritages. In this study, preservation effect by Aquo-Siloxane method towards water permeation and material diffusion were verified. Here one-dimensional permeation and diffusion tests are conducted, and the intrinsic permeability and diffusion coefficient of rock samples with and without AquoSiloxane treatments are evaluated. As rock samples, 3 types of sandstones, such as Berea sandstone, Kimachi sandstone and Isahaya sandstone, and concrete were applied.

One-dimensional permeation tests are conducted towards rock sample with and without Aquo-Siloxane treatment, and intrinsic permeability of samples are evaluated. It is found that the permeability decreases to less than $1 / 10$ to $1 / 100$ of without Aquo-Siloxane treatment, and that Aquo-Siloxane can effectively mitigate the effect of water flow in pores in rocks. The permeation tests conducted during 200 to 600 days, and at several time intervals, intrinsic permeability is measured. As a result, it is also found that the effect gradually develops during more than one year and that the value of intrinsic permeability gradually keeps decreasing.

One-dimensional diffusion tests are also conducted and diffusion coefficient of rock samples with and without Aquo-Siloxane treatment are evaluated. Here, the diffusion processes in rock samples are visualized by X-ray CT scanner system. Then, by comparing CT image data and numerical solutions, diffusion coefficients of rock samples are evaluated. As a result, diffusion coefficients also become smaller by applying Aquo-Siloxane treatments. It means that the AquoSiloxane can also mitigate the effect solute movement in pores of rocks. It is revealed that not only the water permeation but also material movement due to diffusion are efficiently suppressed by applying Aquo-Siloxane method.

As stated above, Aquo-Siloxane method does not shut out the movement of solute but it reduces or mitigates the diffusion same as the effect to water permeation. In other words, Aquo-Siloxane can keep stone heritages in relatively stable condition.

Finally, Aquo-Siloxane method was applied to a stone heritage. It was found that the heritage has been kept in good condition for at least four years.

\section{References}

[1] Al-Omari, A., Beck, K., Brunetaud, X. and Al-Mukhtar, M. (2015) Weathering of 
Limestone on Al-Ziggurat Walls in the Ancient Al-Nimrud City (Iraq). Environmental Earth Sciences, 74, 609-620. https://doi.org/10.1007/s12665-015-4064-9

[2] Maraveas, C. and Tasiouli, K. (2015) Assessment and Restoration of the First Greek Power Plant-Registered Monument of Industrial Heritage. Case Studies in Structural Engineering, 3, 1-10. https://doi.org/10.1016/j.csse.2014.12.001

[3] Torok, A., Szabo, B. and Laszlovszky, J. (2015) Weathering and Preservation of Building Stones and Other Materials: Stone Masonry Material of a Medieval Monastic Glass Production Centre, Pomaz (Hungary). Engineering Geology for Society and Territory-Volume 8: Preservation of Cultural Heritage, 8, 471-475.

[4] Nishiyama, K.-I., Miyamoto, K. and Hasegawa, S. (2014) Evaluation of Weathering Grade of Teshima Stone Used in Lithic Cultural Heritage, Kagawa Prefecture, Japan. Natural Science Research, The University of Tokushima, 28, 45-53.

[5] Carmona-Quiroga, P.M., Blanco-Varela, M.T. and Martinez-Ramirez, S. (2015) Freeze-Thaw and UV Resistance in Building Stone Coated with Two Permanent Anti-Graffiti Treatments. Engineering Geology for Society and Territory-Volume 8: Preservation of Cultural Heritage, 8, 531-534. https://doi.org/10.1007/978-3-319-09408-3_94

[6] Ghobadi, M.H. and Torabi-Kaveh, M. (2014) Assessing the Potential for Deterioration of Limestones Forming Taq-e Bostan Monuments under Freeze-Thaw Weathering and Karst Development. Environmental Earth Sciences, 72, 5035-5047. https://doi.org/10.1007/s12665-014-3373-8

[7] Schiavon, N., De Caro, T., Kiros, A., Caldeira, A.T., Parisi, I.E., Riccucci, C. and Gigante, G.E. (2013) A Multianalytical Approach to Investigate Stone Biodeterioration at a UNESCO World Heritage Site: The Volcanic Rock-Hewn Churches of Lalibela, Northern Ethiopia. Materials Science and Processing-Applied Physics A, 113, 843 854. https://doi.org/10.1007/s00339-013-7757-5

[8] Roussel, E. and Andre, M.-F. (2013) Quantitative Assessment of Pre- and PostRestoration Weathering Rates of Limestone Mayan Temples (Uxmal, Yucatan). Geografia Fisica e Dinamica Quaternaria, 36, 169-179.

[9] Meiklejohn, K.I. (1997) The Role of Moisture in the Weathering of the Clarens Formation of the KwaZulu-Natal Drakensberg: Implications for the Preservation of Indigenous Rock Art. South African Geographical Journal, 79, 199-206.

[10] Heinrichs, K. (2008) Diagnosis of Weathering Damage on Rock-Cut Monuments in Petra, Jordan. Environmental Geology, 56, 643-675. https://doi.org/10.1007/s00254-008-1358-1

[11] Walker, R.A., Wilson, K., Lee, A.F., Woodford, J., Grassian, V.H., Baltrusaitis, J., Rubasinghege, G., Cibin, G. and Dent, A. (2012) Preservation of York Minster Historic Limestone by Hydrophobic Surface Coatings. Scientific Reports, 2, 880. https://doi.org/10.1038/srep00880

[12] Bugani, S., Camaiti, M., Morselli, L., Van De Casteele, E. and Janssens, K. (2008) Investigating Morphological Changes in Treated vs. Untreated Stone Building Materials by X-Ray Micro-CT. Analytical and Bioanalytical Chemistry, 391, 1343-1350. https://doi.org/10.1007/s00216-008-1946-7

[13] Sato, A., Kanayama, S., Obata, M. and Toyomi, A. (2012) Water Retention Characteristics of Aquo-Siloxabe Method Aimed for the Preservation of Stone Cultural Heritages. Journal of MMIJ, 129, 529-537. https://doi.org/10.2473/journalofmmij.129.529

[14] Sato, A. and Ikeda, K. (2015) Visualization of Diffusion Phenomena in the Porous Media by Means of X-Ray CT. Canadian Geotechnical Journal, 52, 1448-1456. https://doi.org/10.1139/cgj-2014-0451 
[15] Sato, A., Kataoka, M., Asaue, H. and Obara, Y. (2012) Applications of X-Ray CT Methods to the Analysis of Transitional Phenomena in Porous Media at X-Earth Center, Kumamoto University. Proceedings of the 2012 World Congress on Advances in Civil, Environmental, and Materials Research, Seoul, 26-29 August 2012, 221-228.

[16] Sato, A., Yoshitake, H., Shiote, T. and Sasa, K. (2011) Development of the Confined Pressure Type of Multi-Purpose Rock Flow System and Its Application to the Evaluation of Permeability of Various Geomaterials. ISRM International Congress on Rock Mechanics-Harmonising Rock Engineering and the Environment, 1357-1360.

[17] Khalid, A.A. and Reed, A.H. (2010) Advances in X-Ray Tomography for Geomaterials. https://doi.org/10.1002/9781118557723

[18] Cnudde, V. (2013) Dominique Bernard. Proceedings of 1st International Conference on Tomography of Materials and Structures.

[19] Sato, A. (2013) Analysis of the Tracer Diffusion Phenomena through Cracks in the Porous Media by Means of X-Ray CT. Materials Sciences and Applications, 4, 18-31. https://doi.org/10.4236/msa.2013.48A003

[20] Sato, A. and Ikeda, K. (2014) $\mu$-Focus CT Observation of Stored $\mathrm{CO}_{2}$ in Porous Media by the Histogram Subtraction Method. Rock Mechanics for Global IssuesNatural Disasters, Environment and Energy, Paper No. CCS-6.

[21] Nakashima, Y. (2006) The Use of X-Ray CT to Measure Diffusion Coefficients of Heavy Ions in Water-Saturated Porous Media. Engineering Geology, 56, 11-17.

[22] Polak, A. (2003) Chemical Diffusion between a Fracture and the Surrounding Matrix: Measurement by Computed Tomography and Modeling. Water Resources Research, 39, SBH 10-1. https://doi.org/10.1029/2001WR000813

[23] Sato, A., Yonemura, H. and Sasa, K. (2010) Analysis of Advection and Diffusion Phenomena in Cracks and into Rock Matrix Parts of Porous Rock by X Rays CT Method. Journal of MMIJ, 126, 647-653. https://doi.org/10.2473/journalofmmij.126.647

[24] Sato, A., Ikeda, K., Yatsunami, T., Tsuda, K., Fukumitsu, T. and Habu, K. (2016) Prevention Effect of Material Flow in the Porous Rocks by Aquo-Siloxane Method. Rock Mechanics \& Rock Engineering: From the Past to the Future, 2, 847-852.

Submit or recommend next manuscript to SCIRP and we will provide best service for you:

Accepting pre-submission inquiries through Email, Facebook, LinkedIn, Twitter, etc. A wide selection of journals (inclusive of 9 subjects, more than 200 journals)

Providing 24-hour high-quality service

User-friendly online submission system

Fair and swift peer-review system

Efficient typesetting and proofreading procedure

Display of the result of downloads and visits, as well as the number of cited articles

Maximum dissemination of your research work

Submit your manuscript at: http://papersubmission.scirp.org/

Or contact msa@scirp.org 